\title{
АНАЛІЗ ФІЗИЧНОЇ АКТИВНОСТІ СТУДЕНТОК ПЕРШОГО РОКУ НАВЧАННЯ В ТЕРНОПІЛЬСЬКОМУ ДЕРЖАВНОМУ МЕДИЧНОМУ УНІВЕРСИТЕТІ IMEНI І. Я. ГОРБАЧЕВСЬКОГО
}

\author{
○Д. В. Попович, О. М. Сопель, В. І. Бондарчук, М. М. Дяченко
}

ДВНз «Тернопільський державний медичний університет імені І. Я. Горбачевського МОз України»

РЕЗЮМЕ. Навчання у вищому навчальному закладі потребує зусиль, напруженої розумової праці. Побут і навчання студенток проходять в умовах обмеженої рухової активності та великого навчального навантаження, стресових ситуацій та неповноцінного харчування.

Мета - вивчити та оцінити рівень фізичної активності студенток першого року навчання в дВН3 «Тернопільський державний медичний університет імені І. Я. Горбачевського МОЗ України».

Матеріал і методи. Проведено анкетування 333 студенткок ДВНЗ «Тернопільський державний медичний університет імені І. Я. Горбачевського МОЗ України», вік опитаних складав 17-19 років. Їм було запропоновано заповнити анкету з демографічної та загальної фізичної активності. В якості методу дослідження використано повну версію анкети «Міжнародна фізична активність» (IPAQ).

Результати. Результати проведеного анкетування продемонстрували доволі високий рівень загальної фізичної активності студенток. Найвищий рівень фізичної активності був під час заняття спортом, а найнижчий - під час домашньої праці. Згідно з дослідженням, більшість опитаних студенток мали нормальну вагу тіла. За результатами дослідження рівня фізичної активності в залежності від кількості вільного часу виявлено, що студентки, які вважали, що вони не мають вільного часу, мали найвищий рівень загальної фізичної активності, так само як і у всіх видах фізичної активності (у роботі, вдома та у спорті). Цілеспрямована праця щодо усвідомлення негативних ефектів гіподинамії повинна була відобразитися на динаміці зміни рівня фізичної активності в бік зменшення. Проте серед студенток на першому році навчання в Університеті простежується різке збільшення кількості осіб із високим рівнем фізичної активності.

Висновки. Студентки першого курсу навчання мають високий рівень фізичної активності (5590,2 MET×xв/тиждень відповідно). Більшість опитаних студенток мали нормальну вагу, лише у 6 \% студенток була надмірна маса тіла. Студентки, які вважали, що вони не мають вільного часу, мали найвищий рівень загальної фізичної активності, а також у всіх видах фізичної активності; таким чином, ці люди більш обґрунтовано та раціонально проводили свій вільний час.

КЛючовІ СЛОВА: фізична активність; «Міжнародна фізична активність» (IPAQ); індекс маси тіла; самооцінка фізичної форми; студентки.

Вступ. На сьогодні здійснено багато досліджень $[6,8,12,17]$, які доводять, що цілеспрямовані заняття різними видами рухової активності сприяють збереженню та зміцненню здоров'я, профілактиці ряду захворювань, підвищенню рівня фізичних і розумових сил та формуванню активної життєвої позиції. Дефіцит фізичної активності негативно позначається на стані здоров'я населення $[13,15]$. Нещодавні дослідження $[8,21]$ обґрунтовують вплив соціальної структури на рівень фізичної активності молоді у всьому світі. Тематичне дослідження фізичної активності студентів університетів, зокрема медичних університетів, $\epsilon$ предметом недавніх досліджень в Південній Азії, Південній Африці, Європі $[16,17,18,19]$ та Україні $[8,21]$. Результати показують, що тенденція до зниження фізичної активності студентів вимагає більшої уваги $[12,15]$, оскільки однією 3 важливих причин порушення нормальних функцій організму у віці 16-18 років $\epsilon$ недостатня рухова активність. Гіпокінезія в першу чергу призводить до зміни стану серцевосудинної системи, яка в похилому віці $\epsilon$ однією з найслабшихих ланок організму. У сучасному суспільстві гіпокінезія зумовлена, насамперед, способом життя людини.

Аналізуючи фізичну активність, в тому числі і фізичний розвиток за показниками індексу маси тіла студентів, за минулі роки, ми виявили, що кількість людей з надмірною вагою та різними типами ожиріння зросла в більшості країн світу, а в розвинених країнах вона стала епідемією та $\epsilon$ суспільно значущою проблемою $[19,20,22]$. В Україні цей показник також високий і $\epsilon$ тенденція до його зростання [2, 4]. М. Дуб, К. Мелега (2012) [4], встановили, що відсоток осіб з надлишковою масою тіла та ожирінням серед студентів вишів, особливо серед дівчат, $\epsilon$ високим (на рівні $20 \%$ ), що пов'язують 3 особливостями студентського способу життя: незбалансоване харчування, низька фізична активність, значні навчальні навантаження, часті стресові ситуації, шкідливі звички. На сьогодні, за даними різних джерел інформації, поширеність проблеми надмірної ваги серед студентської молоді складає 20 \% $[5,11]$. Результати наукових праць засвідчують, що у студентів вищих навчальних закладів простежується тенден- 
Огляди літератури, оригінальні дослідження, погляд на проблему, ювілеї

ція до зниження фізичної активності, що вимагає подальшого вивчення.

Мета - вивчити та оцінити рівень фізичної активності студенток першого року навчання в ДВНЗ «Тернопільський державний медичний університет імені І. Я. Горбачевського МОЗ України».

Матеріал і методи дослідження. Проведено анкетування 333 студенток ДВНЗ «Тернопільський державний медичний університет імені І. Я. Горбачевського МОЗ України», вік опитаних складав 17-19 років. Їм було запропоновано заповнити анкету з демографічної та загальної фізичної активності. В якості методу дослідження використовували повну версію анкети «Міжнародна фізична активність» (IPAQ) [17]. Відповідно до опитувальника International Physical Activity Questionnaire, фізично неактивними вважали осіб, які відповіли, що вони зовсім не займаються помірною або інтенсивною фізичною активністю та ходять менше, ніж 30 хв на день. Опрацювання даних передбачало обчислення величини МЕT (metabolic equivalent of task) - показника, що відображає енергоспоживанняпідчас фізичноїроботи, співвідношення обміну речовин під час специфічної фізичної активності і стану спокою, що аналогічне споживанню 3,5 мл $\mathrm{O}_{2}$ на кг ваги за 1 хв або використанню 1 ккал на 1 кг за 1 год (або 4,184 Дж на 1 кг за 1 год). Значення 3,3 МЕТ, 4,0 МЕТ і 8,0 МЕТ відповідало низькій, середній або значній за потужністю фізичній активності відповідно. Остаточні результати відображали у МЕТ×хв/тиждень. Для аналізу отриманих результатів використовували статистичні методи. Статистичний аналіз проводили за допомогою програми STATISTICA v.10. Достовірними вважали відмінності при р<0,05.

Результати й обговорення. Рівень фізичної активності студенток першого року навчання в університеті має велике значення. За результатами нашого дослідження, Міжнародний опитувальник фізичної активності (IPAQ) $є$ простим у застосуванні і дає інформацію щодо рівня енерговитрат організму студенток для виконання навантажень різної інтенсивності. Результати проведеного анкетування продемонстрували високий рівень загальної фізичної активності студенток (5590,2 МЕТ×хв/тиждень). Найвищий рівень фізичної активності був у студенток під час заняття спортом (1555,4 МЕТ×хв/тиждень), а найнижчий під час домашньої роботи - (1162,2 МЕТ×хв/тиждень). За даними А. В. Цьось, О. З. Касарда та співавт. [13], лише 10,84 \% опитаних свою фізичну активність оцінювали як високу, 71,84 \% - як середню й 17,32 \% - як низьку.

Згідно з нашими дослідженнями, більшість опитаних студенток мали нормальну вагу тіла завдяки високому рівню загальної фізичної актив- ності (5757,6 МЕТ×хв/тиждень). Результати наших досліджень були зіставні з результатами досліджень інших авторів $[14,15,19]$. У результаті аналізу можна стверджувати, що коректний режим дня з регулярними фізичними навантаженнями та збалансована дієта знижують ризик надмірної ваги $[4,8,9]$. У нашому дослідженні $6 \%$ опитаних студенток мали зайву вагу, що було обумовлено відсутністю культури харчування в сім'ї (переїдання), недостатньою фізичною активністю (гіподинамією) та стресовими факторами [7]. Ряд авторів $[5,10]$ вважають, що збільшений індекс маси тіла, ймовірно, пов'язаний з переїданням, недостатньою фізичною активністю та сидячим способом життя. Як відомо, стиль життя студентської молоді нерозривно пов'язаний з інтенсивним навчальним процесом із переважно сидячим способом життя, нераціональним харчуванням та їжею «швидкого приготування», швидкими перекусами чіпсами, цукерками, солодкими напоями, наявністю шкідливих звичок. Такий нездоровий спосіб життя сучасних студентів сприяє швидкому зростанню ваги під час навчання в університеті, що підтверджується іншими авторами $[1,2]$.

За результатами дослідження рівня фізичної активності в залежності від кількості вільного часу у опитаних студенток було встановлено, що студентки, які вважали, що у них немає власного вільного часу, мали найвищий рівень як загальної ФА, так і у всіх видах фізичної активності (у роботі, вдома та у спорті). Студентки, які вважають, що у них вистачає власного вільного часу, мали найнижчий рівень загальної ФА.

Аналізуючи фізичну активність студенток можна стверджувати, що вона висока. Це свідчить про те, що студентська молодь розуміє важливість фізичного складника у формуванні здорового способу життя. Важливо також дотримуватися правил щодо адекватності фізичних навантажень. Це підтверджує необхідність залучення студентів до самостійних і спеціально організованих спортивних занять (секційних занять) у позанавчальний час.

Висновки. Студентки мають високий рівень фізичної активності (5590,2 МЕТ×хв/тиждень). Більшість опитаних студенток мали нормальну вагу, проте 6 \% студенток мали надмірну вагу. Студентки, які вважали, що вони не мали вільного часу, мали найвищий рівень загальної фізичної активності, а також у всіх видах фізичної активності, таким чином, ці люди проводили свій вільний час більш раціонально. Отже, студентки медичного університету насправді усвідомлюють важливість фізичного навантаження у своєму житті і те, що фізична активність $є$ основним фактором здорового способу життя. 
Огляди літератури, оригінальні дослідження, погляд на проблему, ювілеї

Перспективи подальших досліджень. Отримані результати буде застосовано для розробки програми підвищення рівня фізичної активності обстежених студенток, поліпшення їхньої функціональної і фізичної підготовленості та рухової дієздатності.

\section{ЛІТЕРАТУРА}

1. Блавт О. З. Плавання як метод позбавлення хвороби ожиріння студентів спеціального медичного відділення в умовах вузу / О. З. Блавт // Педагогіка, психологія та медико-біологічні проблеми фіз. вих. і спорту. - 2010. - № 1. - С. 17-25.

2. Грибан Г. П. Аналіз стану здоров'я студентів вищих навчальних закладів / Г. П. Грибан, Т. Б. Кутек // Спортивний вісник Придністров'я : [наук.-теорет. журнал Дніпропет. держ. ін-ту фіз. кул. і спорту]. - 2004. № 7.- С. $130-132$.

3. Результати звіту з профілактики фізичної активності дітей та молоді 2014 року в Південній Африці / К. Дрейпер, С. Бассет, Аніза де Вільє, В. Естель // Журнал фізичної активності та здоров'я. - 2014. - № 11 (1). С. 98-103.

4. Дуб М. Сучасні підходи до фізичної реабілітації осіб з надлишковою масою тіла та ожирінням в умовах навчання у вузі / М. Дуб, К. Мелега // Молода спортивна наука України : зб. наук. пр. з галузі фіз. виховання, спорту і здоров'я людини / за заг. ред. Євгена Приступи. - Львів, 2012. - № 16, Т. 3. - С. 87-94.

5. Евдокимова Т. А. Роль физических нагрузок в профилактике и лечении ожирения (обзор литературы) / Т. А. Евдокимова, Е. А. Никитина // Спортивная медицина. -2005 . - № 1. - С. 79-81.

6. Аналіз взаємовідношень між показниками розумової і фізичної працездатності студенток з різним рівнем рухової активності / А. В. Магльований, О. В. Кунинець, О. А. Дзвіненко, О. Ю. Іваночко // Експериментальна та клінічна фізіологія і біохімія. - 2009. № 45). - С. 54-58.

7. Пенгід С. Фізична бездіяльність та пов'язані 3 нею фактори серед однотипних студентів у Південній Африці / С. Пенгід, К. Пелтцер // Африканський журнал для фізичної, освітньої, рекреаційної та танцювальної медицини APHERD. - 2013. - № 19 (л). - С. 143-153.

8. Рівні фізичної активності у жінок-студентів Тернопільського державного медичного університету / Д. В. Попович, Дж. Бергієр, О. М. Сопель, Л. С. Цибульська, М. М. Корда // Міжнародний журнал медицини та медичних досліджень. - 2016. - № 2, Т. 2. - С. 37-41.

9. Романенко В. В. Рухова активність і фізичний стан студенток вищих навчальних закладів : навч. посіб. / В. В. Романенко, О. С. Куц. - Вінниця : ВДМУ, 2003. - 132 С.

10. Рубцова И. В. Оздоровительные технологии на занятиях по физической культуре со студентками, имеющими избыточный вес : дис. на соискание ученой степени канд. пед. наук / И. В. Рубцова. - Малаховка, 2004. -173 с.

11. Строив Ю.И. Ожирение у подростков/Ю.И. Стро- ив, Л. П. Чурилов, Л. А. Чернова, А. Ю. Бельгов. - 2-е изд. Санкт-Петербург : ЭЛБИ, 2006. - 216 с.

12. Тулайдан В. Г. Вплив фізичної активності на якість життя студентів вищих навчальних закладів III-IV рівнів акредитації: автореф. дис. на здобуття наукового ступеню канд. наук з фіз. виховання та спорту :24. 00. 02 / В. Г. Тулайдан. - Львів, 2013. - 22 с.

13. Цьось А. Рухова активність у мотиваційно-ціннісних орієнтаціях студентів / А. Цьось, А. Шевчук, О. Касарда // Фізичне виховання, спорт і культура здоров'я у сучасному суспільстві : зб. наук. пр. Східноєвроп. нац. ун-ту ім. Лесі Українки. - Луцьк : Східноєвроп. нац. ун-т ім. Лесі Українки, 2014. - № 4 (28). - С. 83-87.

14. Чернозуб А. А. Характер изменений состава тела у студентов в процессе занятий физической культурой с использованием комплексов атлетизма / А. А. Чернозуб // Физическое воспитание студентов. - 2011. - № 3. С. $99-102$.

15. Bergier B. Factors determining physical activity of Ukrainian students / B. Bergier, A. Tsos, J. Bergier // Annals of Agricultural and Environmental Medicine. - 2014. Vol. 21, No. 3. - P. 613-616.

16. Physical activity of Polish adolescents and young adults according to IPAQ: a population based study / J. Bergier, L. Kapka-Skrzypczak, P. Biliński [et al.] // Ann. Agric Environ. Med. - 2012. - No. 19 (1) . - P. 109-115.

17. Darren E. R. Health benefits of physical activity: the evidence / E. R. Darren, S. D. Shannon // CMAJ. - 2006. Vol. 174, No. 6. - [Electronic resource]. - Mode access: http://www.cmaj.ca/content/174/6/801.full

18. Guidelines for Data Processing and Analysis of the International Physical Activity Questionnaire (IPAQ) [Electronic resource]. - Mode access: https://docs.google.com/ viewer?a=v\&pid=sites\&srcid=ZGVmYXVsdGRvbWFpbnX0a GVpcGFx

19. BMI indicator and self-assessment of physical activity of students in the visegrad countries /J. Junger, E. Niznikowska, B. Bergier [et al.] // Health Problems of Civilization. - 2016. - No. 10 (4) . - P 14-25.

20. Obesity: epidemiology, pathophysiology, and prevention / D. Bagchi, H. G. Preuss. - Ed. - CRC Press, Taylor \& Francis Group. - 2006. - 569 p.

21. Physical activity levels in female students of Ternopil State Medical University / D. V. Popovych, J. Bergier, O. M. Sopel [et al.] // International Journal of Medicine and Medical Research. - 2016. - Vol. 2. - P. 37-41

22. The problem of obesity in the WHO European region and the strategy for its solution. Summary / Ed. F. Branca, H. Nikogosian, Tim Lobstein. - World Health Organization. $-2007 .-77$ p. 
Огляди літератури, оригінальні дослідження, погляд на проблему, ювілеї

\section{REFERENCES}

1.Blavt, O.Z. (2010). Plavanniayak metod pozbavlennia khvoroby ozhyrinnia studentiv spetsialnoho medychnoho viddilennia v umovakh vuzu [Swimming as a method of depriving a student of obesity of a special medical department in a university] Pedahohika, psykholohiia ta medyko-biolohichni problemy fiz. vykh. i sportu - Pedagogy, Psychology and Medical-biological Problems of Physical Training and Sports, 1, 17-25 [in Ukrainian].

2. Hryban, H.P. (2004). Analiz stanu zdorovia studentiv vyshchykh navchalnykh zakladiv [Analysis of the health status of students of higher educational institutions]. Sportyvnyivisnyk Prydnistrovia:[nauk.-teoret. zhurnal Dnipropet. derzh. in-tu fiz. kul. i sportu] - Sports Herald of Prydnistrovia: [Sci.-Theoret. Journal of Dnipropetrovsk State Institute of Physical Training and Sports, 7, 130-132 [in Ukrainian].

3. Dreiper, K., Basset, S., Aniza de Vilie, Estel Lambert, V., \& grupa pysma HAKSA (2014). Rezultaty zvitu z profilaktyky fizychnoi aktyvnosti ditei ta molodi 2014 roku v Pivdennii Afrytsi [Results of the report on the prevention of physical activity of children and young people in South Africa in 2014]. Zhurnal fizychnoi aktyvnosti ta zdorovia - Journal of Physical Activity and Health, 11 (1), 98-103 [in Ukrainian].

4. Dub, M. \& Meleha, K. (2012). Suchasni pidkhody do fizychnoi reabilitatsii osib z nadlyshkovoiu masoiu tila ta ozhyrinniam v umovakh navchannia u vuzi [Modern approaches to physical rehabilitation of persons with excess body weight and obesity in conditions of studying in high school]. Prystupa Ye. (Ed.) Moloda sportyvna nauka Ukrainy: zb. nauk. pr. z haluzi fiz. vykhovannia, sportu $i$ zdorovia liudyny - Young Sports Science of Ukraine: Collection of Scientific Works on Physical Education, Sport and Human Health, 16, 3, 87-94 [in Ukrainian].

5. Evdokimova, T.A., \& Nikitina, E.A. (2005). Rol fizicheskikh nagruzok $v$ profilaktike i lechenii ozhyreniya (obzor literatury) [The role of physical activity in the prevention and treatment of obesity (literature review)]. Sportivnaya meditsina - Sport Medicine, 1, 79-81 [in Russian].

6. Mahlovanyi, A.V., Kunynets, O.V., Dzvinenko, O.A. \& Ivanochko, O.Yu. (2009). Analiz vzaiemovidnoshen mizh pokaznykamy rozumovoi i fizychnoi pratsezdatnosti studentok z riznym rivnem rukhovoi aktyvnosti [Analysis of the relationship between the indicators of mental and physical capacity of students with different levels of motor activity]. Eksperymentalna ta klinichna fiziolohiia i biokhimiia-Experimental and Clinical Physiology and Biochemistry, 1 (45), 54-58 [in Ukrainian].

7. Penhid, S. \& Pelttser, K. (2013). Fizychna bezdiialnist ta poviazani z neiu faktory sered odnotypnykh studentiv u Pivdennii Afrytsi [Physical inactivity and related factors among students of the same type in South Africa]. Afrykanskyi zhurnal dlia fizychnoi, osvitnoi, rekreatsiinoi ta tantsiuvalnoi medytsyny APHERD. - African Journal of Physical, Educational, Recreational and Dance Medicine APHERD, 19 (l), 143-153 [in Ukrainian].

8. Popovych, D.V., Berhiier, Dzh., Sopel, O.M., Tsybulska, L.S., \& Korda, M.M. (2016). Rivni fizychnoi aktyvnosti u zhinok-studentiv Ternopilskoho derzhavnoho medychnoho universytetu [Levels of physical activity in female students of the Ternopil State Medical University]. Mizhnarodnyi zhurnal medytsyny ta medychnykh doslidzhen - International Journal of Medicine and Medical Research, 2 (2), 37-41 [in Ukrainian].
9. Romanenko, V.V. \& Kuts, O.S. (2003). Rukhova aktyvnist $i$ fizychnyi stan studentok vyshchykh navchalnykh zakladiv [Activity and physical condition of students of higher educational institutions]. Vinnytsia: VDMU [in Ukrainian].

10. Rubtsova, I.V. (2004). Ozdorovitelnye tekhnologii na zanyatiyakh po fizicheskoy kulture so studentkamy, imeyushimi izbytochnyy ves [Improvement technologies at physical education classes with students with overweight]. Candidate's thesis [in Russian].

11. Stroiv, Yu.I., Churylov, L.P., Chernova, L.A. \& Belgov, A.Yu. (2006). Ozhyrenye u podrostkov [Obesity in adolescents]. Saint-Peterburg: ELBI [in Russian].

12. Tulaidan, V.G. (2013). Vplyv fizychnoi aktyvnosti na yakist zhyttia studentiv vyshchykh navchalnykh zakladiv III-IV rivniv akredytatsii [Influence of physical activity on the quality of life of students of higher educational institutions of III-IV accreditation levels]. Candidate's Extended abstract. Lviv [in Ukrainian].

13. Tsis, A., Shevchuk, A., \& Kasarda, O. (2014). Rukhova aktyvnist u motyvatsiino-tsinnisnykh oriientatsiiakh studentiv [Activity in students' motivational and value orientations]. Fizychne vykhovannia, sport i kultura zdorovia u suchasnomu suspilstvi: zb. nauk. pr. Skhidnoievrop. nats. un-tu im. Lesi Ukrainky - Physical Education, Sport and Health Culture in Modern Society: Collection of Scientific Works of Eastern Europe National University by Lesia Ukrainka. Lutsk: Eastern European National University by Lesia Ukrainka, 4 (28), 8387 [in Ukrainian].

14. Chernozub, A.A. (2011). Kharakter izmeneniy sostava tela u studentov $v$ protsesse zanyatiy fizicheskoy kulturoy s ispolzovanyem kompleksov atletizma [The character of changes in the body composition of students in the process of physical culture classes using the athletic complexes]. Fizicheskoye vospitanye studentov - Physical Education of Students, 3, 99-102 [in Russian].

15. Bergier, B., Tsos, A., \& Bergier, J. (2014). Factors determining physical activity of Ukrainian students. Annals of Agricultural and Environmental Medicine, 21, 3, 613-616.

16. Bergier, J., Kapka-Skrzypczak, L., Biliński, P., Paprzycki, P. \& Wojtyta, A. (2012). Physical activity of Polish adolescents and young adults according to IPAQ: a population based study. Ann. Agric Environ. Med., 19 (1), 109-115.

17. Darren, E.R. \& Shannon, S.D. (2006). Health benefits of physical activity: the evidence. CMAJ March 14, 174, 6, [Electronic resource]. Retrieved from: http://www.cmaj. ca/content/174/6/801.full

18. Guidelines for Data Processing and Analysis of the International Physical Activity Questionnaire (IPAQ) [Electronic resource]. Retrieved from: https://docs.google.com/view er?a=v\&pid=sites\&srcid=ZGVmYXVsdGRvbWFpbnx0aGVpcGFx

19. Junger, J., Niznikowska, E., Bergier, B., Fromel, K., Sallona, F., Acs, P., \& Bergier, J. (2016). BMI indicator and selfassessment of physical activity of students in the visegrad countries. Health Problems of Civilization, 10 (4), 14-25.

20. Bagchi, D., \& Preuss, H.G. (2006). Obesity: epidemiology, pathophysiology, and prevention. CRC Press, Taylor \& Francis Group. 569.

21. Popovych, D.V., Bergier, J., Sopel, O.M., Tsybulska, L.S. \& Korda, M.M. (2016). Physical activity levels in female students of Ternopil State Medical University. International Journal of Medicine and Medical Research. 2, 37-41. 
Огляди літератури, оригінальні дослідження, погляд на проблему, ювілеї

22. Branca, F., Nikogosian, H., \& Lobstein Tim (2007).

The problem of obesity in the WHO European Region

and the strategy for its solution. Summary. World Health

Organization, 77.

\title{
АНАЛИЗ ФИЗИЧЕСКОЙ АКТИВНОСТИ СТУДЕНТОК ПЕРВОГО ГОДА ОБУЧЕНИЯ В ТЕРНОПОЛЬСКОМ ГОСУДАРСТВЕННОМ МЕДИЦИНСКОМ УНИВЕРСИТЕТЕ ИМЕНИ И. Я. ГОРБАЧЕВСКОГО
}

\author{
๑Д. В. Попович, О. Н. Сопель, В. И. Бондарчук, М. М. Дьяченко
}

ГВУЗ «Тернопольский государственный медицинский университет имени И. Я. Горбачевского МОЗ Украчны»

РЕЗЮМЕ. Обучение в вузе требует усилий, напряженной умственной работы. Быт и обучение студенток проходят в условиях ограниченной двигательной активности и большой учебной нагрузки, стрессовых ситуаций, и также неполноценного питания.

Цель - изучить и оценить уровень физической активности студенток первого года обучения в гвУз «Тернопольский государственный медицинский университет имени И. Я. Горбачевского МОЗ Украины».

Материал и методы исследования. Проведено анкетирование 333 студенток ГВУз «Тернопольский государственный медицинский университет имени И. Я. Горбачевского МЗ Украины", возраст опрошенных составлял 17-19 лет. Респондентам было предложено заполнить анкету по демографической и общей физической активности. В качестве метода исследования использована анкета «Международная физическая активность» (IPAQ) в полной версии.

Результаты. Результаты проведенного анкетирования показали довольно высокий уровень общей физической активности студенток. Наивысший уровень физической активности продемонстрировали студентки во время занятий спортом, а самый низкий - во время домашней работы. Согласно исследованию, большинство опрошенных студенток имели нормальный вес тела. По результатам исследования уровня физической активности в зависимости от количества свободного времени у опрошенных студенток выявлено, что студентки, считающие, что они не имели свободного времени, имели самый высокий уровень общей физической активности, так же как и во всех видах физической активности (в работе, дома и в спорте).

Выводы. Студентки первого года обучения имеют высокий уровень физической активности (5590,2 МЕТ×мин/в неделю). Большинство опрошенных студенток имели нормальный вес, однако 6 \% студенток имели избыточный вес. Студентки, считающие, что они не имеют свободного времени, имели самый высокий уровень общей физической активности, а также во всех видах физической активности; таким образом, эти люди проводили свое свободное время более обоснованно и рационально.

КЛЮчЕВЫЕ СЛОВА: физическая активность; «Международная физическая активность» (IPAQ); индекс массы тела; самооценка физической формы; студентки.

\section{ANALYSIS OF PHYSICAL ACTIVITY OF WOMAN STUDENTS OF THE FIRST YEAR OF STUDIES AT I. HORBACHEVSKY TERNOPIL STATE MEDICAL UNIVERSITY}

\author{
@D. V. Popovych, O. M. Sopel, V. I. Bondarchuk, M. M. Diachenko \\ I. Horbachevsky Ternopil State Medical University
}

SUMMARY. Learning at a higher educational institution requires effort, intense mental work. The life and study of students take place in conditions of limited motor activity and a large training load, stressful situations, as well as malnutrition.

The aim - to study and evaluate the level of physical activity of students in the first year of studies at I. Horbachevsky Ternopil State Medical University.

Material and Methods. A questionnaire was conducted for 333 students of I. Horbachevsky Ternopil State Medical University, the age of the respondents was 17-19 years. They were asked to complete a questionnaire on demographic and general physical activity. As a method of study, the International Physical Activity (IPAQ) questionnaire was used in full version.

Results. The results of the survey showed a high level of general physical activity of the students. The highest level of physical activity was demonstrated in the students during the sport, and the lowest - during domestic work. According to the study, most of the students surveyed had a normal body weight. According to the results of the study of the physical activity level, depending on the amount of free time in the surveyed students, it was proved that those who consider that they had no free time had the highest level of general physical activity, as well as in all types of physical activity (in work, at home and in sports).

Conclusions. Students have a high level of physical activity (5590.2 MET×min/week). Most of the students surveyed had a normal weight, but $6 \%$ of the students were overweight. Students who believed that they had no free time had the highest level of general physical activity, as well as in all types of physical activity, thus, these people spent their free time more reasonably.

KEY WORDS: physical activity; "International physical activity" (IPAQ); woman students. 